\title{
Transvaginal color Doppler sonography in adnexal masses: which parameter performs best?
}

\author{
J. L. Alcázar, M. L. Ruiz-Perez and T. Errasti
}

Department of Obstetrics and Gynecology, Clínica Universitaria de Navarra, School of Medicine, University of Navarre, Pamplona, Spain

Key words: TRANSVAGINAI. SONOGRAPHY, COLOR DOPPLER, ADNEXAL MASS

\begin{abstract}
The aim of this study was to establish which of several commonly used parameters perforns best in the evaluation of adnexal masses by transuaginal color Doppler sonography. A total of 79 adnexal masses in 73 consecutive patients were included in the study. There were $43(58.9 \%)$ premenopausal and $30(41.1 \%)$ postmenopausal patients. The median age was 45 years (range 20-78 years). The parameters compared were: number of vessels detected in cach tumor, tumor vessel location (central u's. peripheral), peak systolic velocily (PSV), lowest resistance index $\left(R I_{\text {lowest }}\right)$, mean resistance index ( $\left.R I_{\text {mean }}\right)$, lowest pulsatility index ( $\left.P I_{\text {lowest }}\right)$ and mean pulsatility index $\left(P I_{\text {mean }}\right)$. Receiver operating characteristic (ROC) curves were plotted to analyze the test performance of the parameters, except for tumor vessel location, and to estimate the best cut-off value of the parameters studied to differentiate between malignant and benign tumors. Definitive histopathological diagnosis was obtained in every case and used as the 'gold standard'. There were $20(25.3 \%)$ malignant and 59 $(74.7 \%)$ benign masses. Color Doppler signals were detected in $100 \%$ of the malignant masses (20 out of 20 ) and $74.6 \%$ (44 out of 59) of the benign masses, and the difference was found to be statistically significant ( $\mathrm{p}<0.001)$. Tumor vessel location was central in 18 out of 20 (90\%) malignant masses, whereas it was peripheral in 39 out of $44(88.6 \%)$ benign masses. ROC analysis showed that the best cut-off values for number of vessels, PSV, RI $I_{\text {lowest, }}$, $R I_{\text {mean }}, P I_{\text {lowest }}$ and $P I_{\text {mean }}$ were three vessels, $25 \mathrm{~cm} / \mathrm{s}, 0.45$, $0.55,0.90$ and 1.50, respectively. However, for all these parameters except $R I_{\text {lowest }}$, there was a considerable overlap between benign and malignant tumors, with a high falsepositive rate. In conclusion, in our experience, the parameters that performed best were the $R I_{\text {lowest }}$ with a cut-off value of 0.45 (sensitivity $100 \%$; false-positive rate $11.4 \%$ )
\end{abstract}

and central tumor vessel location (sensitivity 90\%; falsepositive rate $11.4 \%$ ).

\section{INTRODUCTION}

Sonography has been widely used to evaluate adnexal masses. The introduction of transvaginal ultrasonography has improved the diagnostic accuracy of ultrasound in the characterization of adnexal masses ${ }^{1,2}$. With the introduction of pulsed and color Doppler techniques the assessment of tumor vascularity has become feasible ${ }^{3}$.

In recent years, several studies have assessed the value of transvaginal color Doppler sonography in the differentiation of malignant from benign adnexal tumors ${ }^{4-17}$. The results of these studies have been controversial. Most have assessed impedance to tumor vessel blood flow by calculating one or both angle-independent indexes of flow velocity wavcform analysis, i.c. the resistance index (RI) and pulsatility index (PI). Whilst some authors have reported quite encouraging results ${ }^{4-6}$, others have not been able to confirm them and have shown considerable overlapping of the values of these two indices between malignant and benign tumors $7,9,11,12,15$.

Recently, some authors have advocated the assessment of different aspects of tumor vascularity such as vessel location $^{18}$, vessel arrangement ${ }^{18}$ and multiparameter analy$\operatorname{sis}^{19}$, in order to improve the diagnostic accuracy of transvaginal color Doppler sonography in assessment of adnexal masses.

In the present study we aimed to compare the test performance of several parameters commonly used in the evaluation of adnexal tumors by transvaginal color Doppler sonography.

Correspondence: Dr J. L. Alcázar, Department of Obstetrics and Gynecology, Clínica Universitaria de Navarra, Avda Pio XII s/n, 31080 Pamplona, Spain 


\section{MATERIAIS AND METHODS}

Between October 1994 and November 1995, 73 consecutive and unselected patients diagnosed as having an adnexal mass and referred for surgery to our hospital were included in the study. Six patients presented bilateral masses, giving a total of 79 adnexal tumors in the study.

All patients were evaluated by transvaginal color Doppler sonography before surgery. A definitive histopathological diagnosis was obtained in each case and used as the 'yold standard'. Tumors were classified according to criteria of the World Health Organization ${ }^{20}$. Malignancies were staged according to the International Federation of Obstetrics and Gynecology (FIGO) ${ }^{21}$.

There were $30(41.1 \%)$ postmenopausal patients (median age 58 years; range $42-78)$ and $43(58.9 \%$ ) premenopausal patients (median age 36 years; range 20-45). All premenopausal patients except six were studied during the follicular phase of the menstrual cycle.

Transvaginal color Dopplcr ultrasonography was carried out on a Philips P-700 SE machine (Philips Ultrasound, Santa Ana, CA, USA) with a real-time $6.5-\mathrm{MHz}$ sector electronic array endovaginal probe with pulsed Doppler and equipped with the Colour Velocity Imaging (CVI) system for color blood flow codification ${ }^{22}$. The high-pass filter was set at $100 \mathrm{~Hz}$ in every case. The pulsed Doppler sample volume was set at $1.2-2 \mathrm{~mm}$. The system operates at power outputs of less than $80 \mathrm{~mW} / \mathrm{cm}^{2}$ in the B-image, pulsed Doppler and CVI modes.

The endovaginal probe was inserted into the vagina, and the uterus was scanned. Thereafter, attention was directed to the adnexal regions. Once the adnexal mass was identified, it was thoroughly scanned.

Morphological evaluation was performed according to the scoring system proposed by Sassone and colleagues ${ }^{2}$. Briefly, it evaluates the tumor wall thickness, the presence of septae and/or papillary projections and their size, and tumor echogenicity. A score of $\geq 9$ was suspicious of malignancy.

Thereafter, the CVI gate was activated for color imaging of blood flow. When color signals were detected, they were counted and localized in each tumor. The location of tumor vessels was stated as central (solid areas, septa and/or papillae) or peripheral (pericystic areas or those at the base of septa or papillae). In cases in which blood flow was detected both in central and peripheral locations, the tumor was classified as having central flow.

Pulsed Doppler was used to interrogate each color signal detected and a fluw velocity waveform was obtained in each case (Figure 1). The RI and the PI were calculated from three cardiac cycles, according to the following formulae: $\mathrm{RI}=$ (peak systolic velocity - maximum end-diastolic velocity)/peak systolic velocity; and PI = (peak sys tolic velocity - end-diastolic velocity)/mean flow velocity. Maximum peak systolic velocity (PSV) was recorded in each vessel. No angle correction was made, because the vessels studied were too small to allow this, although we always attempted to obtain the highest Doppler shift to measure the PSV. If there was more than one artery within

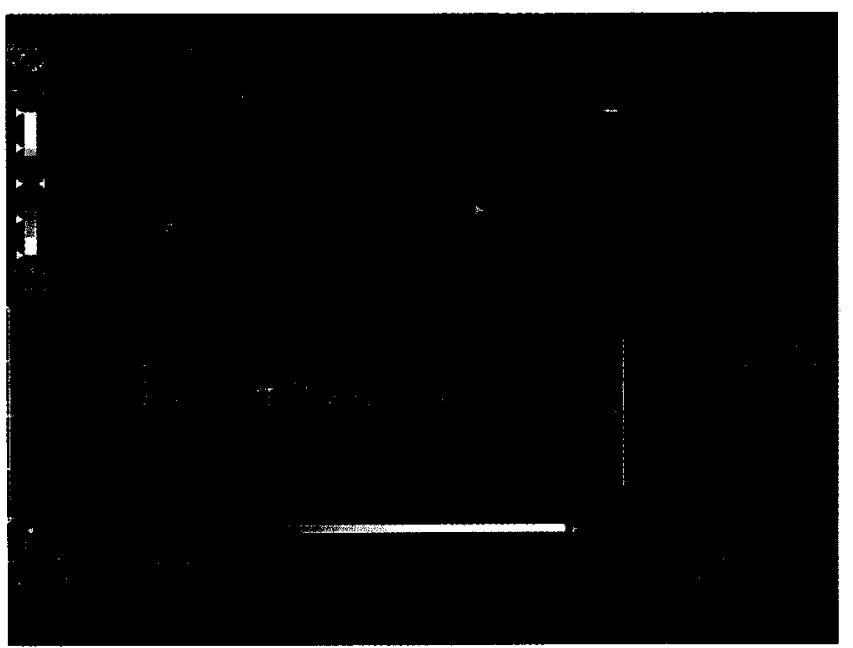

Figure 1 Flow velocity waveform from an endometriotic cyst. Note the presence of flow in a septum. RI, 0.48; PI, 0.77

a given tumor, then the RI and PI were calculated for each onc of these vessels. We analyzed as different parameters the lowest value ( $\left.\mathrm{RI}_{\text {lowest }}, \mathrm{PI}_{\text {lowest }}\right)$ and the mean of them ( $\mathrm{RI}_{\text {mean }}, \mathrm{PI}_{\text {mean }}$ ).

All examinations were performed by one of the authors (J.L.A.). The intra-observer coefficient of variation was determined by the performance of three consecutive examinations at $30-\mathrm{min}$ intervals in the first 15 masses studied. Intra-observer variability for the RI, PI, PSV and number of vessels counted was $6 \%, 7 \%, 12 \%$ and $4 \%$, respectively. The median examination time was $12 \mathrm{~min}$, ranging from 5 to 35 min.

The Mann-Whitney $U$ test and Fisher's exact test were used where appropriate. The data are expressed as mean and standard deviation (SD). Confidence intervals (CIs) were calculated when appropriate. A $p$-value of $\leq 0.05$ was considered to be statistically significant.

Receiver operating characteristic $(\mathrm{ROC})^{2.3}$ curves were plotted to analyze the test performance of each parameter, except for tumor vessel location. For each parameter assessed, the cut-off value that had the highest sensitivity with the lowest false-positive rate was considered to be optimal.

Data analyses were performed with the SPSS 6.0 for Windows statistical package (SPSS Inc., Chicago, Il).

\section{RESULTS}

Surgical confirmation was available in all cases. Twenty $(25.3 \%)$ masses were proved to be malignant, and 59 $(74.7 \%)$ were benign. Borderline malignant tumors were considered to be malignant for analyses. The definitive histological diagnoses and stages of malignant tumors are shown in lable 1 . The mean $( \pm \mathrm{SD})$ score in benign and malignant masses was $5.9 \pm 1.6$ and $10.8 \pm 1.2$, respectively ( $U$ value $66.3 ; p<0.001$ ).

Color Doppler signals were detected in $100 \%(20 / 20)$ of malignant masses and in $74.6 \%$ (44/59) of benign 
Table 1 Definitive histopathological diagnoses

\begin{tabular}{lc}
\hline Histopathology & Masses $(n)$ \\
\hline Benign & 14 \\
Serous cystadenoma & 3 \\
Mucinous cystadenoma & 19 \\
Endometrioma & 3 \\
Dermoid cyst & 5 \\
Follicular cyst & 4 \\
Paraovarian cyst & 3 \\
Cystadenofibroma & 2 \\
Hydrosalpinx & 2 \\
Hemorrhagic cyst & 2 \\
Luteal cyst & 1 \\
Peritoneal pseudocyst & 1 \\
Benign granulosa cell tumor & 59 \\
Total & \\
Malignant & 2 \\
Borderline malignant carcinoma & \\
Primary ovarian carcinoma & \\
Metastatic carcinoma & \\
Total & 5 \\
Total & 20 \\
\hline
\end{tabular}

"Stage Ib, one patient (bilateral mass); stage Ic, two patients; stage IIIa, one patient (bilateral mass); stage IIIc, five patients (two bilateral masses). ${ }^{\dagger}$ Endometrium (two patients), rectum (one patient), carcinoid (one patient, bilateral mass)

masses (Fisher's exact test, $p=0.009$ ). The location of color Doppler signals was central in 18 out of $20(90 \%)$ malignant masses and peripheral in 39 out of $44(88.6 \%)$ of benign tumors (Fisher's exact test, $p<0.001$ ). The mean $( \pm$ SD) number of color Doppler signals in benign and malignant tumors was $1.70 \pm 1.5$ and $8.30 \pm 5.5$, respectively ( $U$ value $77.5 ; p<0.001$ ) (Figure 2 ).

The mean maximum peak systolic velocities ( \pm SD) were $27.6 \pm 12.6 \mathrm{~cm} / \mathrm{s}$ in benign masses and $44.6 \pm 5.2 \mathrm{~cm} / \mathrm{s}$ in malignant tumors ( $U$ value $146 ; p<0.001$ ). Individual values are shown in Figure 3.

The mean $\mathrm{RI}_{\text {lowest }}, \mathrm{RI}_{\text {mean }}, \mathrm{PI}_{\text {lowest }}$ and $\mathrm{PI}_{\text {mean }}$ in benign and malignant masses are shown in Table 2. Figures 4 and 5 show the individual values for each of these parameters. There were no differences between primary and metastatic ovarian carcinomas (Table 3).

Figure 6 depicts the ROC curves for score, number of vessels per tumor, PSV, RI $\mathrm{I}_{\text {lowest }}, \mathrm{RI}_{\text {mean }}, \mathrm{PI}_{\text {lowest }}$ and $\mathrm{PI}_{\text {mean }}$. The best cut-off values estimated for each parameter were: score $\geq 9$ (sensitivity $100 \%$; false-positive rate $6.8 \%$, with $95 \%$ CI 12.3-1); > 3 vessels (sensitivity $95 \%$, with $95 \% \mathrm{CI}$ $100-90$; false-positive rate $25.4 \%$, with $95 \%$ CI $34.4-$ 16.4); PSV $\geq 25 \mathrm{~cm} / \mathrm{s}$ (sensitivity $85 \%$, with $95 \%$ CI $93.7-$ 76.5; false-positive rate $56.8 \%$, with $95 \%$ CI $69.1-44.4$ ); lowest $\mathrm{RI} \leq 0.45$ (sensitivity $100 \%$; false-positive rate $11.4 \%$, with $95 \%$ CI 19.2-3.6); mean RI $\leq 0.55$ (sensitivity $90 \%$, with $95 \% \mathrm{CI} 97.3-82.7$; false-positive rate $18.2 \%$, with $95 \%$ CI $27.6-8.8$ ); $\mathrm{PI}_{\text {lowest }} \leq 0.90$ (sensitivity $95 \%$, with $95 \%$ CI 100-90; false-positive rate $20.5 \%$, with 95\% CI 30.4-10.6); and $\mathrm{PI}_{\text {mean }} \leq 1.50$ (sensitivity $100 \%$; false-positive rate $29.6 \%$, with $95 \%$ CI $40.6-18.6$ ).

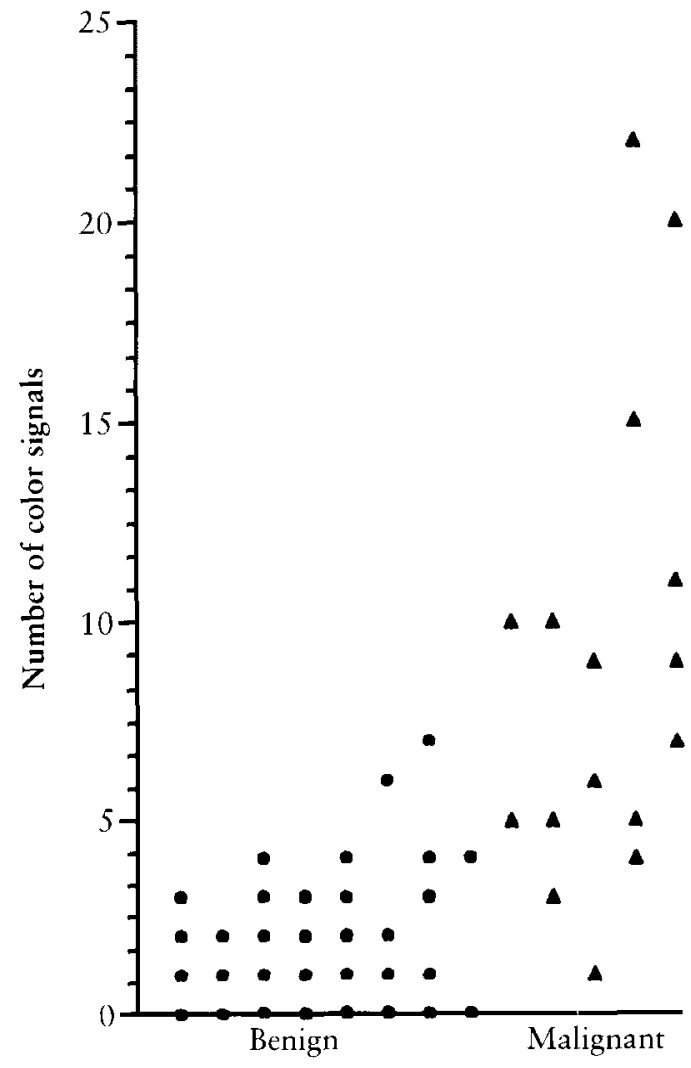

Figure 2 Scatterplot showing the number of vessels detected per tumor in benign and malignant masses

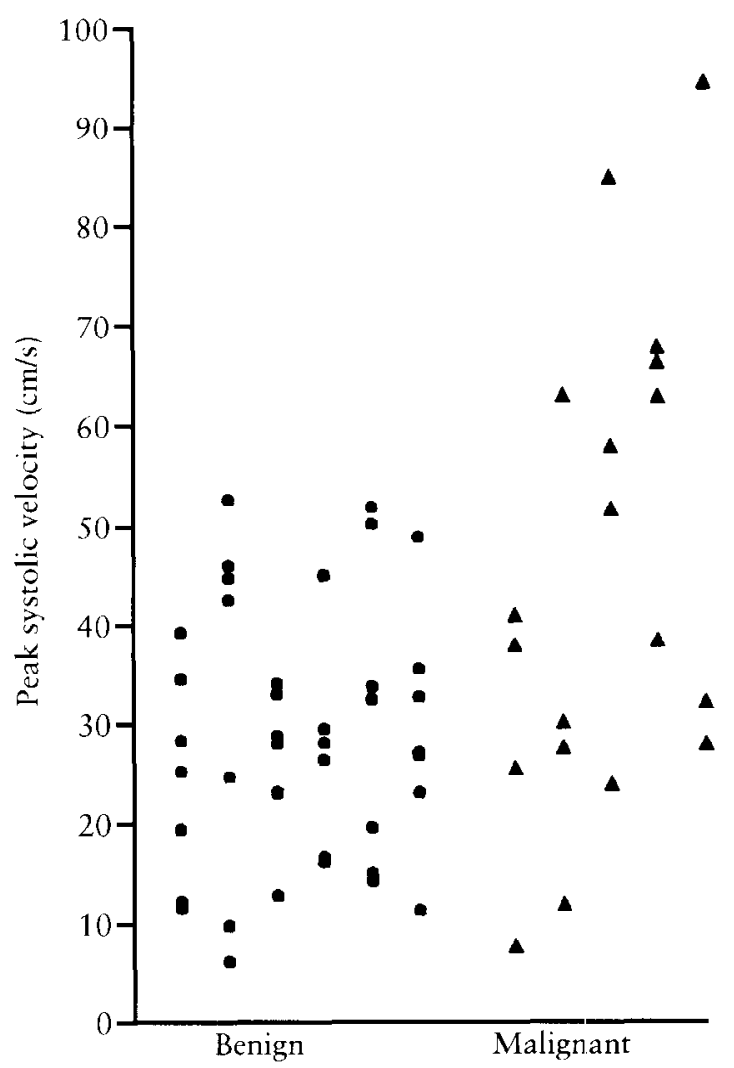

Figure 3 Scatterplot showing the distribution of mean peak systolic velocity in benign and malignant adnexal masses 


\section{DISCUSSION}

Transvaginal sonography is a well-established technique for examining pelvic organs. Special interest has been focused on the assessment of adnexal masses ${ }^{1}$. With the introduction of color and pulsed Doppler techniques, efforts have been made to improve the diagnostic accuracy of transvaginal sonography in the differentiation of benign from malignant tumors.

(a)

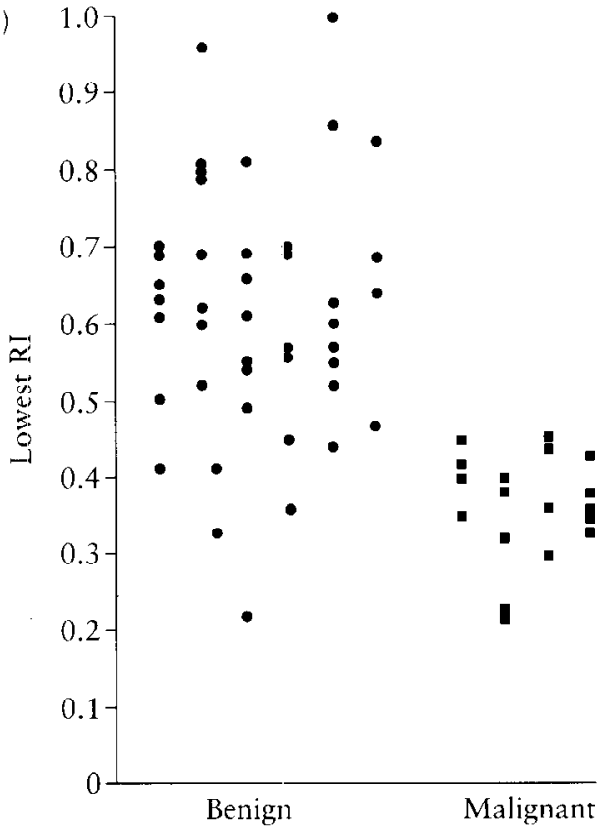

Table 2 Mean \pm SD of resistance index $(\mathrm{RI})$ and pulsatility index (PI) values in tumors shown by histopathology to be benign or malignant

\begin{tabular}{lcc}
\hline & Benign $(n=59)$ & Malignant $(n=20)$ \\
\hline Lowest RI & $0.62 \pm 0.15$ & $0.37 \pm 0.07^{*}$ \\
Mean RI & $0.67 \pm 0.13$ & $0.46 \pm 0.06^{*}$ \\
Lowest PI & $1.50 \pm 0.87$ & $0.55 \pm 0.15^{*}$ \\
Mean PI & $1.76 \pm 0.87$ & $0.80 \pm 0.24^{*}$ \\
\hline
\end{tabular}

$* p<0.0001$ (Mann-Whitney U test)

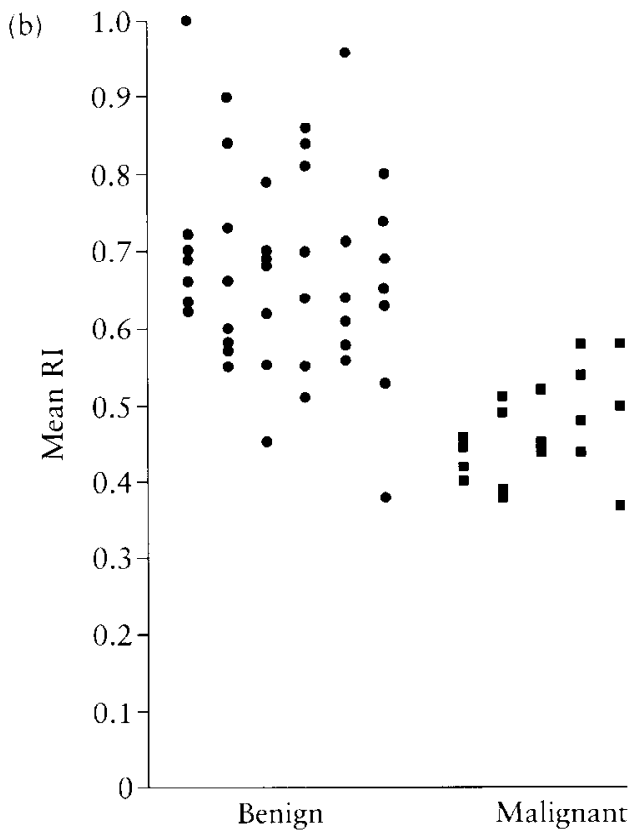

Figure 4 Distribution of lowest RI (a) and mean RI (b) in benign and malignant adnexal masses
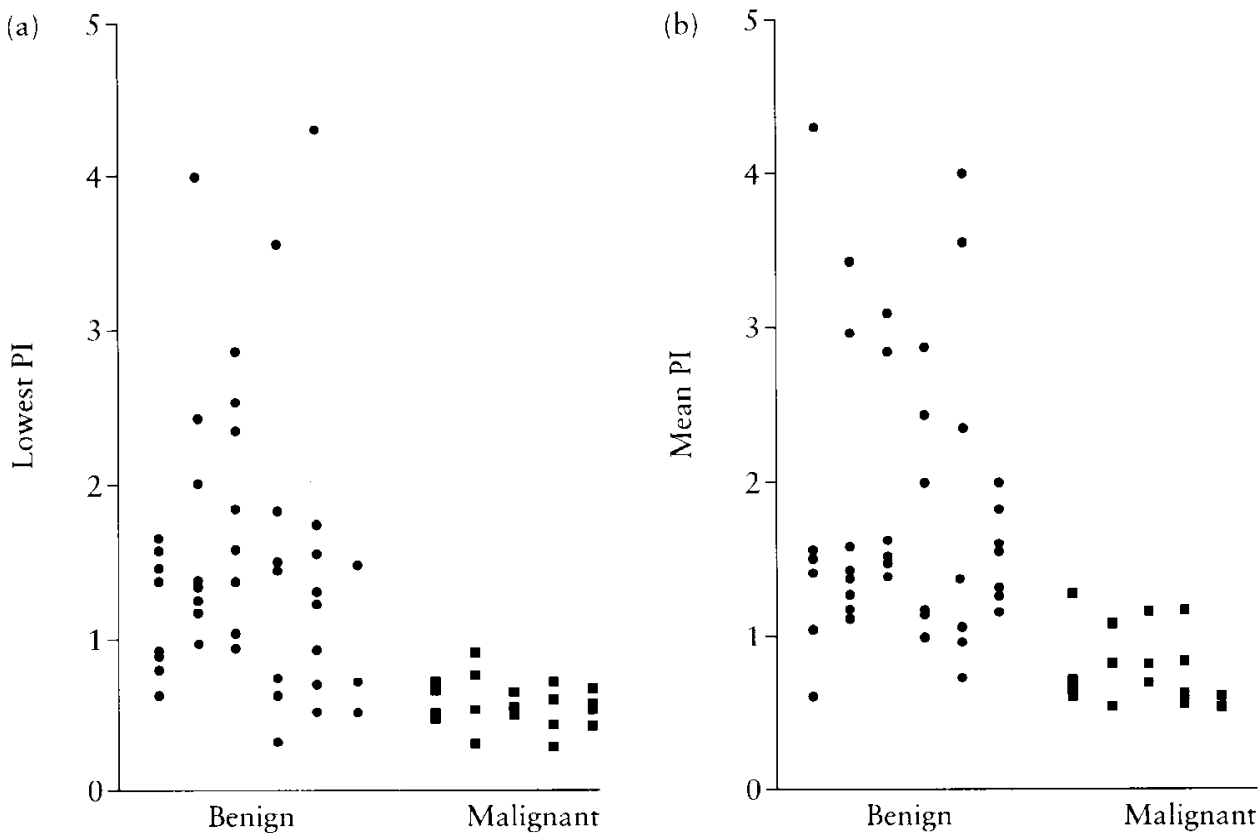

Figure 5 Distribution of lowest PI (a) and mean PI (b) in benign and malignant adnexal masses 
Table 3 Mean \pm standard deviation values for different parameters compared in primary and metastatic ovarian carcinomas

\begin{tabular}{|c|c|c|}
\hline & Primary $(n=15)^{*}$ & Metastatic $(n=5)$ \\
\hline Score & $10.9 \pm 1.1$ & $11.0 \pm 1.6^{\dagger}$ \\
\hline Mean PVS $(\mathrm{cm} / \mathrm{s})$ & $4.3 .6 \pm 4.8$ & $46.3 \pm 6.9^{\dagger}$ \\
\hline No vessels & $8.15 \pm 6.19$ & $8.40 \pm 3.05^{\dagger}$ \\
\hline Mean RI & $0.45 \pm 0.06$ & $0.46 \pm 0.05^{\dagger}$ \\
\hline Lowest RI & $0.35 \pm 0.07$ & $0.39 \pm 0.04^{\dagger}$ \\
\hline Mean PI & $0.77 \pm 0.22$ & $0.78 \pm 0.29^{\dagger}$ \\
\hline Lowest PI & $0.53 \pm 0.17$ & $0.58 \pm 0.11^{\dagger}$ \\
\hline
\end{tabular}

PVS, peak systolic velocity; RI, resistance index; PI, pulsatility index; "including two borderline malignant tumors; ${ }^{\dagger} p>0.05$

Early studies were encouraging. Kurjak and associates ${ }^{4}$ reported a sensitivity and specificity of $96.4 \%$ and $99.8 \%$, respectively, in a large series of adnexal tumors. Weiner and colleagues ${ }^{5}$ and Kawai and co-workers ${ }^{6}$ reported, in smaller series, a sensitivity and specificity of $94 \%$ and $97 \%$, and $89 \%$ and $100 \%$, respectively. However, recent studies have not confirmed these results, showing a lower degree of accuracy with this technique ${ }^{7.9-12}$. Some factors put forward to explain these misleading results include differences in the sonographers' experience, the different sensitivity of ultrasound machines used and the lack of standardization of Doppler measurements ${ }^{24}$.

Nevertheless, most authors have assessed adnexal tumor vascularity, evaluating the location of vessels and blood flow impedance of these tumor vessels. With regards to vessel location, most authors agree that central location is suggestive, although not diagnostic, of tumor malignancy $3,18,19,25$. Our results agree with these studies. The sensitivity and specificity for this parameter were $90 \%$ and $88.6 \%$, respectively. However, this could be explained by the fact that most benign tumors were cystic and vessels could be located only peripherally. Nevertheless, in multilocular cysts or cystic lesions with solid areas, the presence of blood flow in the septa or solid areas should be considered to be suspicious of malignancy, especially if low resistance is detected in pulsed Dopplcr analysis. In our experience, there were two false-negative cases. One was a multilocular, cystic, borderline malignant, serous cystadenocarcinoma with several peripheral vessels identified and a value of $\mathrm{RI}_{\text {lowss }}=0.44$ at the base of a septum. The other case was a stage Ib serous cystadenocarcinoma that was cystic, with a papillary projection on gray-scale ultrasound, and a unique vessel at the base of this papillary projection with an RI of 0.42 .

On the other hand, we had five benign tumors classified as having central flow, i.e. in septa or solid areas. All these cases except one had a value of $\mathrm{RI}_{\text {loverst }}$ above 0.45 .

Regarding blood flow impedance, most authors have assessed two angle-independent indices of flow velocity waveform spectral analysis: the RI and PI. Some authors have established clear cut-off values to differentiate benign from malignant tumors. Kurjak and associates ${ }^{4}$ suggest that an RI of $\leq 0.40$ is suspicious of malignancy. However, others have proposed RI cut-off values of $0.50^{14}$ or even $0.60^{15}$. Weiner and colleagues ${ }^{5}$ proposed a PI cut-off valuc

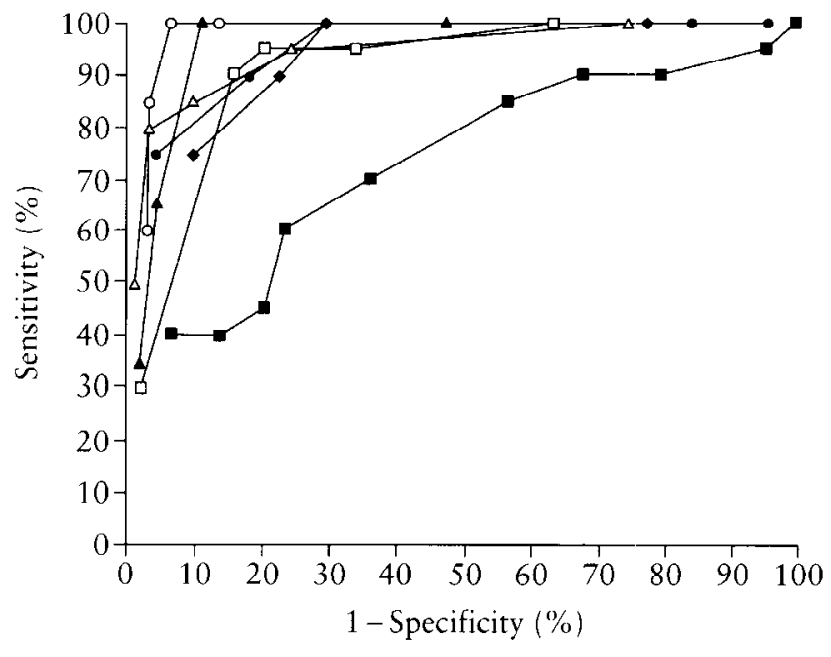

Figure 6 Receiver operating characteristic curves based on all 79 tumors. The false-posirive rate is 1 - specificity. Cut-off values for each parameter (shown from right to left): score (open circles) $\geq 11, \geq 10, \geq 9, \geq 8$; number of vessels per tumor (open triangles) $\geq 1, \geq 3, \geq 5, \geq 7$; lowest PI (open squares) $\leq 1.50, \leq 1, \leq 0.90$, $\leq 0.75, \leq 0.50$; mean peak systolic velocity $(\mathrm{cm} / \mathrm{s}$; closed squares) $\geq 5, \geq 10, \geq 15, \geq 20, \geq 25, \geq 30, \geq 35, \geq 40, \geq 45, \geq 50$; lowest RI (closed triangles) $\leq 0.60, \leq 0.45, \leq 0.40, \leq 0.35$; mean RI (closed circles) $\leq 0.90, \leq 0.80, \leq 0.60, \leq 0.55, \leq 0.50$; mean PI (closed diamonds) $, \leq 1.75, \leq 1.50, \leq 1.15, \leq 1$

of $\leq 1.0$, but Kawai and co-workers ${ }^{6}$ proposed a PI cut-off value of $\leq 1.25$.

However, recent reports have shown considerable over lapping, both of the RI and PI, between benign and malignant tumors ${ }^{7,9,11,12,17}$. Most of these studies concluded that, although both indices tend to be lower in malignant tumors, it was not possible to establish a practical cut-off value.

If the RI or PI is to be used, then which index is most efficient at differentiating benign from malignant tumors ${ }^{26}$ ? Most authors agree that the lowest RI or PI detected should be used. However, we speculated that an averaged value of all RI or PI values from all vessels detected within a tumor could potentially give more precise information of overall tumor vascularization. However, from our data, it seems that the lowest value should be used, for both RI and PI. The lowest and mean values of RI and PI showed similar sensitivity, but the false-positive rate was higher using $R I_{\text {mean }}$ and $P I_{\text {mean }}$.

In our experience, the overlapping of $\mathrm{PI}_{\text {lowest }}$ values among benign and malignant tumors makes it difficult to establish a clear cut-off value. These results are similar to those reported by other groups, which found a falsepositive rate ranging from 24 to $76 \%$ with the use of a cut-off value of $\mathrm{PI}_{\text {lowess }}<1.0^{7,9,11,12.17}$. However, the use of a cut-off value of $\mathrm{RI}_{\text {lowest }} \leq 0.45$ had a sensitivity of $100 \%$ with an acceptable specificity of $88.6 \%$. Therefore, the lowest RI seems to be better than the lowest PI to differentiate benign from malignant adnexal masses.

In our series the mean PSV in malignant tumors was significantly higher than in benign masses. However, there was a considcrablc ovcrlap in values (see Figure 3), making 
it difficult to establish a clear cut-off value. These results agree with those reported by Valentin and co-workers ${ }^{11}$ and Prömpeler and colleagues ${ }^{16}$.

In conclusion, our results showed that the parameter that was able to differentiate most effectively between malignant and benign adnexal tumors with transvaginal color Doppler ultrasonography was the lowest RI. However, we would not propose that it should be used alone, but in conjunction with other parameters such as tumor vessel location and peak systolic velocity.

\section{REFERENCES}

1. Granberg, S., Norström, A. and Wikland, M. (1990). Tumors in the lower pelvis as imaged by vaginal sonography. Gynecol. Oncol., 37, 224-9

2. Sassone, A. M., Timor-Tritsch, I. E., Artner, A., Westhoff, C. and Warren, W. B. (1991). Transvaginal sonography characterization of ovarian disease: evaluation of a new scoring system to predict ovarian malignancy. Obstet. Gynecol., 78, $70-6$

3. Fleischer, A. C., Rodgers, W. H., Rao, B. K., Kepple, D. M., Worrell, S. A., W'illiams, L. and Jones, H. W. III (1991). Assessment of ovarian tumor vascularity with transvaginal color Doppler sonography. J. Ultrasound Med., 10, 563-8

4. Kurjak, A., Zalud, I. and Alfirevic, Z. (1991). Evaluation of adnexal masses with transvaginal color Doppler. J. Ultrasound Med., 10, 295-7

5. Weiner, Z., Thaler, I., Beck, D., Rottem, S., Deutsch, M, and Brandes, J. M. (1992). Differentiating malignant from benign ovarian tumors with transvaginal color flow imaging. Obstet. Gynecol., 79, 159-62

6. Kawai, M., Kano, T., Kikkawa, F., Maeda, O., Oguchi, H. and Tomoda, Y. (1992). Transvaginal Doppler ultrasound with color flow imaging in the diagnosis of ovarian cancer. Obstet. Gynecol., 79, 163-7

7. Tekay, A. and Jouppila, P. (1992). Validity of pulsatility and resistance indices in classification of adnexal tumors with transvaginal color Doppler ultrasound. Ultrasound Obstet. Gynecol., 2, 338-44

8. Timor-Tritsch, I. E., Lerner, J. P., Monteagudo, A. and Santos, R. (1993). Transvaginal ultrasonographic characterization of ovarian masses by means of color flow-directed Doppler measurements and a morphologic scoring system. Am. J. Obstet. Gynecol., 168, 909-13

9. Hamper, U. M., Sheth, S., Abbas, F. M., Rosenshein, N. B., Aronson, D. and Kurman, R. J. (1993). Transvaginal color Doppler sonography of adnexal masses: differences in blood flow impedance in benign and malignant lesions. Am. J. Roentgenol., 160, 1225-8

10. Bromley, B., Goodman, H. and Benacerraf, B. R. (1994). Comparison between sonographic morphology and Doppler waveform for the diagnosis of ovarian malignancy. Obstet. Cynecol., 83, 434-7

11. Valentin, L., Sladkevicius, P. and Marsal, K. (1994). Limited contribution of Doppler velocimetry to the differential diag- nosis of extrauterine pelvic tumors. Obstet. Gynecol., 83, $425-33$

12. Brown, D. L., Frates, M. C., Laind, F. C., DiSalvo, D. N., Doubilet, P. M., Benson, C. B., Waitzkin, E. D. and Muto, M. G. (1994). Ovarian masses: can benign and malignant lesions be differentiated with color and pulsed Doppler US? Radiology, 190, 333-6

13. Kawai, M., Kikkawa, F., Ishikawa, H., Tamakoshi, K., Maeda, O., Hasegawa, N., Mizuno, K., Suzuki, A., Itakura, A., Nakashima, N. and Tomoda, Y. (1994). Differential diagnosis of ovarian tumors by transvaginal color-pulse Doppler sonography. Gynecol. Oncol., 54, 209-14

14. Chou, C.-Y., Chang, C. H., Yao, B.-L. and Kuo, H.-C. (1994). Color Doppler ultrasonography and serum CA-125 in the differentiation of benign from malignant ovarian tumors. $J$. Clin. Ultrasound, 22, 491-6

15. Zanetta, G., Vergani, P. and Lissoni, A. (1994). Color Doppler ultrasound in preoperative assessment of adnexal masses. Acta Ohstet. Gynecol. Scand., 73, 637-41

16. Prömpeler, H. J., Madjar, H., Sauerbrei, W., Lattermann, U. and Pfleiderer, A. (1994). Quantitative flow measurements for classification of ovarian tumors by transvaginal color Doppler sonography in postmenopausal patients. Ultrasound Obstet. Gynecol., 4, 406-13

17. Stein, S. M., Laifer-Narin, S., Johnson, M. B., Roman, L. D., Muderspach, L. I., Tyszka, J.M. and Ralls, P. W. (1995). Differentiation of benign and malignant adnexal masses: relative value of gray-scale, color Doppler and spectral Doppler sonography. Am.J. Roentgenol., 164, 381-6

18. Kurjak, A., Predanic, M., Kupesic-Urek, S. and Jukic, S. (1993). Transvaginal color and pulsed Doppler assessment of adnexal tumor vascularity. Gynecol. Oncol., 50, 3-9

19. Fleischer, A. C., Rodgers, W. H., Kepple, D. M., Williams, L. L. and Jones, H. W. III (1993). Color Doppler sonography of ovarian masses: a multiparameter analysis. J. Ultrasound Med., 12, 41-8

20. Serov, S. F., Scully, R. E. and Sobin, L. H. (1973). International Histological Classification of Tumors. No. 9, Histological Typing of Ovarian Tumors. (Geneva: World Health Organization)

21. Shepcrd, J. H. (1989). Reviscd FIGO staging for gynecological cancer. Br. J. Obstet. Gynaecol., 96, 889-92

22. Pcsquc, P. (1990). Colour velocity imaging: a technology that bypasses Doppler and measures blood flow directly. Hospimedica, 8, 60-6

23. Richardson, D. K., Schwartz, J. S., Wcinbaum, P. J. and Gabbe, S. G. (1985). Diagnostic tcsts in obstetrics: a method for improved evaluation. Am. J. Obstet. Gynecol., 152, 61318

24. Kurjak, A. and Kupesic, S. (1995). Transvaginal color Doppler and pelvic tumor vascularity: lessons learned and future challenges. Ultrasound Obstet. Gynecol., 6, 145-59

25. Kurjak, A. and Predanic, M. (1992). New scoring system for prediction of ovarian malignancy based on transvaginal color Duppler sonography. J. Ultrasound Med., 11, 631-8

26. Hall, G. M. (1991). Highest or lowest values of impedance flow in malignancy? Ultrasound Obstet. Gynecol., 1, 374 